\title{
Society for Advanced Bronchoscopy Consensus Statement and Guidelines for bronchoscopy and airway management amid the COVID-19 pandemic
}

\author{
Michael A. Pritchett ${ }^{1}$, Catherine L. Oberg ${ }^{2}$, Adam Belanger ${ }^{3}$, Jose De Cardenas ${ }^{4}$, George Cheng ${ }^{5}$, \\ Gustavo Cumbo Nacheli ${ }^{6}$, Carlos Franco-Paredes ${ }^{7,8}$, Jaspal Singh ${ }^{9}$, Jennifer Toth ${ }^{10}$, Michael Zgoda ${ }^{9}$, \\ Erik Folch ${ }^{11}$ \\ ${ }^{1}$ FirstHealth of the Carolinas and Pinehurst Medical Clinic, Pinehurst, NC, USA; ${ }^{2}$ David Geffen School of Medicine at UCLA, Los Angeles, CA, \\ USA; ${ }^{3}$ University of North Carolina School of Medicine, Chapel Hill, NC, USA; ${ }^{4}$ University of Michigan School of Medicine, Ann Arbor, MI, USA; \\ ${ }^{5}$ University of California, San Diego, CA, USA; ${ }^{6}$ Spectrum Health, Michigan State University School of Human Medicine, Grand Rapids, MI, USA; \\ ${ }^{7}$ University of Colorado Anschutz Medical Center, Aurora, CO, USA; ${ }^{8}$ Hospital Infantil de Mexico, Federico Gomez, Mexico City, Mexico; ${ }^{9}$ Atrium \\ Health and Levine Cancer Institute, Charlotte, NC, USA; ${ }^{10}$ Penn State Health, Hershey Medical Center, Hershey, PA, USA; ${ }^{11}$ Massachusetts \\ General Hospital, Harvard Medical School, Boston, MA, USA \\ Correspondence to: Michael A. Pritchett, DO, MPH. FirstHealth of the Carolinas and Pinehurst Medical Clinic, 205 Page Road, Pinehurst, NC 28374, \\ USA. Email: mpritchett@pinehurstmedical.com.
}

Submitted Mar 20, 2020. Accepted for publication Apr 03, 2020.

doi: $10.21037 /$ jtd.2020.04.32

View this article at: http://dx.doi.org/10.21037/jtd.2020.04.32

\section{Introduction}

The severe acute respiratory syndrome coronavirus 2 (SARS-CoV-2) is a newly emerging zoonotic virus that was initially identified in Wuhan City, Hubei Province, China on December 30, 2019 and spread rapidly via human-tohuman transmission chains that existed before containment control measures were implemented. At the time of this writing, cases of coronavirus disease 2019 (COVID-19), caused by SARS-CoV-2, have been reported in 184 countries (https://coronavirus.jhu.edu/map.html), leading to the outbreak being classified as a pandemic by the World Health Organization (WHO) on March 11, 2020 (1). COVID-19 infection, in many cases, requires specialized airway management in intensive care units (ICU). Similar to the SARS pandemic in 2003, this viral infection appears to be a highly transmissible pathogen in healthcare environments, including transmission to healthcare personnel.

As the COVID-19 pandemic evolves worldwide, healthcare systems and providers struggle to strike a balance between providing medical care to those in need while limiting disease spread and exposure to patients and staff. The Society for Advanced Bronchoscopy (SAB) has formulated guidelines regarding bronchoscopy and airway management in this setting in an effort to summarize the currently available information and provide practical, evidence-based recommendations for those caring for or being asked to consider performing these high-risk procedures. Members of the $\mathrm{SAB}$ established a panel of practitioners, prioritized current challenges in the field to effectively respond to the pandemic, agreed on group processes, and provided full declaration of conflicts of interest. In preparing this document, and to the best of our knowledge, we performed an in-depth review of existing medical literature. We subsequently developed sequential evaluations of the quality of evidence across studies for specific situations that we may encounter as advanced bronchoscopists and interventional pulmonologists. We based the grade of recommendation on the quality of supporting evidence and the balance between benefits and harms (Table 1) (2).

In this rapidly changing public health environment, we also acknowledge that best practices may vary amongst institutions based on local resources, expertise, patient populations, and continual updating of recommendations from major health organizations such as the US Centers for Disease Control and Prevention (www.cdc.gov) and the WHO (www.who.int). Therefore, we are planning to update the protocols and recommendations outlined here (www. 
Table 1 Grade of recommendation based on the quality of supporting evidence

\begin{tabular}{|c|c|c|c|}
\hline Grade & Strength & Evidence quality & Descriptor \\
\hline $1 \mathrm{C}$ & Strong recommendation & Low & $\begin{array}{l}\text { Evidence obtained from observational studies, nonsystematic clinical experience with } \\
\text { significant potential benefit and low risk of harm }\end{array}$ \\
\hline $2 \mathrm{~B}$ & Weak recommendation & Moderate & $\begin{array}{l}\text { Existing randomized trials with important flaws and the ratio of benefit and risk is } \\
\text { closely balanced; further evidence is unlikely to change our confidence on this ratio }\end{array}$ \\
\hline $2 \mathrm{C}$ & Weak recommendation & Low & $\begin{array}{l}\text { Existing observation studies, nonsystematic clinical experience, or controlled trials } \\
\text { with serious flaw in their design; any estimate of effect is unclear }\end{array}$ \\
\hline
\end{tabular}

sabronchoscopy.org) as we inevitably learn new information that will affect our practices and procedures. We are also planning to evaluate our recommendations in terms of their applicability and barriers to their implementation.

\section{SARS-CoV-2 and COVID-19 infection}

SARS-CoV-2 is a betacoronavirus similar to that which caused the SARS epidemic in 2003. The incubation period is up to 14 days, though data from China revealed that most symptoms begin $4-5$ days after exposure $(3,4)$. The virus is transmitted from person to person via respiratory droplets that are either inhaled or deposited on mucous membranes. Droplets do not usually travel more than 6 feet. Other transmission routes include contact with contaminated fomites and inhalation of contaminated aerosols (5). While fecal shedding has been demonstrated, the fecal-oral route does not appear to be a driver of transmission (6).

The most common presenting symptoms of COVID-19 are fever, fatigue, dry cough, and dyspnea. Less commonly reported symptoms include headache, sore throat, cough with sputum production, diarrhea and ageusia/anosmia (7). Chest imaging will often show bilateral ground-glass opacities with or without consolidation or pneumonitis, consistent with a viral pneumonia (8). While people are most contagious when they are symptomatic, cases of asymptomatic transmission have been reported (9).

The majority of infections do not produce profound disease, however, $15 \%$ of those infected may develop significant respiratory symptoms such as severe dyspnea, tachypnea, and hypoxemia; 5\% may develop critical illness including respiratory failure, acute respiratory distress syndrome (ARDS), shock, and/or multiorgan failure (10). In a case series of more than 72,300 cases in China, the overall mortality was $2.3 \%$; however when stratified by age, no deaths occurred in patients 9 years old and younger; meanwhile, the mortality rate among those 80 years and older was $14.8 \%$ (10). Notably, nearly half of all critical care cases were fatal. According to the WHO-China Joint Mission on Coronavirus Disease 2019, the overall case fatality rate in China was $0.7 \%$ with most cases occurring in those of advanced age or with comorbid conditions, such as cardiovascular disease, diabetes, hypertension, and chronic respiratory disease $(6,10)$.

\section{Outpatient bronchoscopy considerations}

We recognize that many hospitals have decided to cancel all elective procedures and, in some cases, closed down entire endoscopy units. While some bronchoscopy procedures are indeed elective, most are for more acute/subacute issues, including for the diagnosis and staging of malignancy.

Deciding how to stratify outpatient bronchoscopic procedures to minimize the risk of infection transmission, while not compromising time-sensitive medical care, is a major challenge facing bronchoscopists during this pandemic. We recommend reviewing the need for all procedures on a case-by-case basis to assess the indications and urgency, such that cases be appropriately scheduled or rescheduled based on pre-determined clinical priorities (Figure 1).

Certain emergent situations warrant immediate, sameday action, including acute foreign body aspiration, massive hemoptysis, and severe, symptomatic central airway obstruction. In cases of massive hemoptysis with 


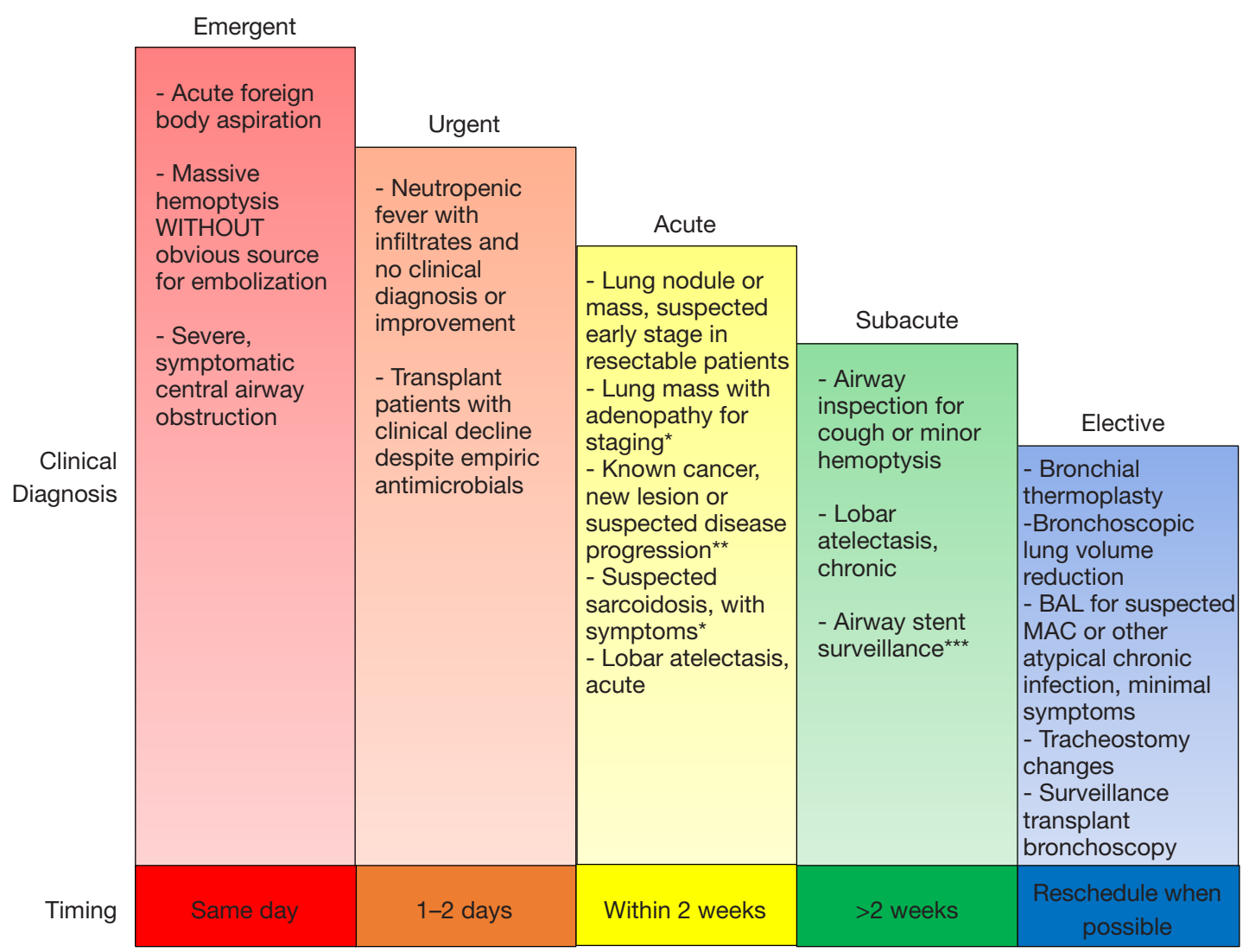

Figure 1 Stratification of outpatient bronchoscopic procedures by urgency. *, when no other target present. **, where biopsy will alter treatment plans. ${ }^{* * *}$, should not be more than 2 weeks after the pre-determined surveillance window. BAL, bronchoalveolar lavage; MAC, Mycobacterium avium complex.

imaging findings such as large cavitary lesions or masses, we recommend consideration of arterial embolization as the procedure of choice unless airway stabilization is needed. In immunocompromised patients (e.g., patients with febrile neutropenia, solid organ or stem cell transplantation) who (I) are not responding to empirical antimicrobial coverage, (II) are test-negative for COVID-19, and (III) have no other diagnostic means available, urgent bronchoscopy in 1 to 2 days may be warranted.

In cases of suspected or confirmed lung cancer, bronchoscopic biopsy and staging procedures are often essential and cannot be delayed indefinitely, as significant delays in surgery or radiotherapy could result in disease progression $(11,12)$. We therefore recommend that bronchoscopy be performed within 2 weeks for asymptomatic/ COVID-19-negative patients who have a lung nodule suspicious for early-stage cancer, a lung nodule or mass with adenopathy who need diagnosis and staging, or a known lung cancer with possible progression of disease where biopsy will alter the treatment course.

We recognize that these recommendations are based on expert opinion and limited data in a rapidly evolving crisis. However, timely interventions for patients with early lung cancer will be required in non-endemic areas as well as in cancer centers that can secure enough personal protective equipment (PPE) and personnel to continue to provide oncologic care. The trade-off between timely care and risk of exposure to SARS-CoV-2 is a pressing matter for patients and healthcare providers. Current ASCO and NCCN recommendations cautiously guide clinicians towards standard infection control practices and individualized decision-making based on the patient's best interest. The American College of Surgeons published their guidelines for triage of surgical cases and considered semi-urgent cases as those where survivorship would be compromised if surgery is not performed within 3 months. This category included solid or predominantly solid lung cancer or presumed lung cancer $>2 \mathrm{~cm}$ with clinical node negative, 
node positive lung cancer, post-induction therapy cancer staging to star treatment, esophageal stenting, symptomatic mediastinal tumors and patients enrolled in therapeutic clinical trials (13).

Additionally, patients with acute lobar atelectasis, as well as those with symptomatic suspected sarcoidosis without an alternative biopsy site for diagnosis, should also have their procedure completed in this 2 -week time frame. Routine airway stent surveillance evaluations should be performed in the typical time frame of 4-6 weeks after placement and should not be delayed for more than 2 weeks.

In subacute patients who have been scheduled for an airway inspection for chronic lobar obstruction or hemoptysis, as well as those in whom a lavage is needed for the diagnosis of suspected chronic atypical infection such as non-tuberculous mycobacterium, procedures should be deferred for 2 weeks or more. Finally, purely elective procedures such as bronchial thermoplasty, bronchoscopic lung volume reduction, routine tracheostomy changes, and routine surveillance bronchoscopy in transplant patients should be deferred indefinitely until elective cases are considered to be relatively safe to resume.

\section{Screening of patients for outpatient bronchoscopy}

We recommend broad screening and mitigation strategies prior to scheduling procedures and again prior to arrival for planned endoscopic procedures. Specifically, at the time of scheduling, patients should be asked about symptoms, contacts and travel history regardless of the planned procedure. If the patient has increased risk factors or signs and symptoms of an active viral infection, the procedure should be delayed, if possible.

Once scheduled, the patient should be contacted, and screening questions should be repeated the day before the procedure. If the patient reports respiratory symptoms due to an unexplained cause, the procedure should be rescheduled according to the specific patient's disease and condition and the patient referred for COVID-19 evaluation as per local practice standards. When the patient reaches the hospital, the facility-specific screening protocol should be followed to stratify the risk of COVID-19 patients. Pertinent questions may include the following:

(I) Have you had fever $\left(>37.5^{\circ} \mathrm{C}\right)$, cough, sore throat, or respiratory problems in the past 14 days?
(II) Have you had close contact with a suspicious or confirmed case of COVID-19?

(III) Have you visited or currently live in areas at higher risk of COVID-19 in the last 14 days?

If the answer is yes to any of the above questions, we recommend delaying the procedure if clinically feasible.

Upon arrival at the outpatient department, we recommend checking the temperature of both the patient and their caregiver, using non-contact methods before being allowed to enter the bronchoscopy suite/operating room. If either the patient or caregiver have a temperature above $37.5^{\circ} \mathrm{C}$, the procedure should be cancelled, and the affected parties should be rescreened and tested for COVID-19 per institutional protocol.

During this period of pandemic, accompanying caregivers and relatives of the patients should be limited to one per patient to minimize exposure and waiting room crowding. Visitors are prohibited from entering the bronchoscopy preparation area unless the patient requires specific assistance or translation services.

\section{Infection control recommendations for the healthcare team}

\section{Hand bygiene}

Frequent hand washing with soap and water or alcoholbased solutions is the single most important hygiene measure in protection against cross infection and must be actively enforced. Alcohol-based hand sanitizer should be located at or near every workstation. Hand hygiene should be meticulously performed according to standard guidelines, specifically after removing gloves, after contact with soiled or contaminated areas, before touching any equipment needed for intubation or bronchoscopy; essentially after every contact with the patient (e.g., placement of thermometer or nasogastric tube).

\section{PPE}

Thoracic endoscopic procedures generate aerosols and droplets $(14,15)$. Thus, there must be a compelling indication prior to performing any type of endoscopy in a patient with suspected or confirmed COVID-19 infection (16). PPE, which encompasses gowns, masks, eye shields and gloves, is key to minimizing transmission; it should be available to all personnel participating in endoscopic procedures. Performing hand hygiene is essential before donning and after doffing PPE (17). 
Table 2 PPE recommendations and respirator conservation measures. How to safely reuse and store the personal protection equipment The CDC has offered guidance on reuse and extended use of PPE considering the current shortages (https://www.cdc.gov/niosh/topics/hcwcontrols/ recommendedguidanceextuse.html)

\begin{tabular}{|c|c|c|c|}
\hline \multirow{2}{*}{ Recommendation } & \multicolumn{3}{|c|}{ PPE recommendations: indications, use and storage } \\
\hline & Low-risk procedures & High-risk aerosolization procedures & $\begin{array}{l}\text { Suspected or confirmed COVID-19, } \\
\text { all procedures }\end{array}$ \\
\hline \multirow{2}{*}{$\begin{array}{l}\text { Personal } \\
\text { protective } \\
\text { equipment }\end{array}$} & $\begin{array}{l}\text { Mask with attached face shield OR } \\
\text { Isolation mask plus goggles }\end{array}$ & N95 plus goggles OR PAPR & N95 plus goggles OR PAPR \\
\hline & Should wear gown and gloves & Should wear gown and gloves & Should wear gown and gloves \\
\hline Conservation & & $\begin{array}{l}\text { PAPR: Wipe w/Oxivir- } 1 \text { wipes after each } \\
\text { use. Reuse between patients unless } \\
\text { hood integrity becomes compromised }\end{array}$ & $\begin{array}{l}\text { PAPR: Wipe w/Oxivir-1 wipes after each } \\
\text { use. Reuse between patients unless } \\
\text { hood integrity becomes compromised }\end{array}$ \\
\hline Safe storage & & $\begin{array}{l}\text { PAPR: label hood with your name } \\
\text { and store in a secure area to prevent } \\
\text { contamination }\end{array}$ & $\begin{array}{l}\text { PAPR: label hood with your name } \\
\text { and store in a secure area to prevent } \\
\text { contamination }\end{array}$ \\
\hline
\end{tabular}

Reproduced with permission from Laraine Washer, MD, Division of Infectious Diseases, University of Michigan. PAPR, powered air purifying respirators.

\section{Masks/respirators}

The N95 mask is a particulate filtering facepiece respirator that is approved for protection against droplet and airborne transmission of $95 \%$ of particles greater than 0.3 microns in size (18). It does not protect against gases or vapors. This mask requires fit testing prior to its use in healthcare settings. Persons with robust facial hair may have difficulty with proper fit of these masks and should refer to the CDC for specific information regarding facial hairstyles and respirators (19). Healthcare worker infections with influenza and SARS have been reported in personnel not using N95 mask and PPE $(20,21)$.

We recognize that supply chains are being disrupted and materials are becoming scarce; therefore, particularly with N95 masks, practices of extended use and reuse may become necessary and are outlined by the CDC (https://www.cdc.gov/niosh/topics/hcwcontrols/ recommendedguidanceextuse.html) (Table 2). Traditional surgical masks have been recommended for healthcare professionals in prior coronavirus epidemics. It is important to mention that the size of the virion is between 125-244 microns (including spikes) while the N95 masks protect against transmission of $95 \%$ of particles greater than $300 \mathrm{~nm}$ (22). This apparent discrepancy supports the idea that transmission mostly occurs by droplets. The experience with prior epidemics of SARS as well as two randomized controlled trials of transmission of influenza virus (80$120 \mathrm{~nm}$ ) in nurses, further support the notion that droplet precaution is the most important factor in exposure of healthcare personnel $(20,23)$. These randomized controlled trials support the finding that neither N95 respirators nor medical masks are more effective in preventing influenza or other viral respiratory infection. Thus, definitive evidence of greater clinical effectiveness of N95 is lacking. Furthermore, most particles from human expiratory activities (breathing, talking, singing, coughing, sneezing) generate droplets between 580 and $5,420 \mathrm{~nm}$ (5.2 micrometer) $(24,25)$.

In the prior epidemics, the experience of Vietnam and Toronto suggest that the type of mask is not as important as the consistent use of surgical mask or N95 mask $(26,27)$. The experience of these diverse healthcare groups found the consistent use of surgical masks or N95 to be protective of SARS. Both studies also emphasize the importance of PPE for mucosal protection. Given the highly contagious nature of SARS-CoV-2, healthcare personnel are recommended to 
maximize their level of protection by using the N95 mask.

Superior protection might be achieved with a powered air-purifying respirator (PAPR) (18). This is a batterypowered blower that provides protection against gases, particles and vapors. Fit testing is not required and it can be used with facial hair (14). The PAPR also provides simultaneous eye protection. Availability of PAPR systems is limited in most healthcare settings.

\section{Donning and doffing PPE}

Proper donning (putting on) and doffing (taking off) of PPE is essential to reduce exposure to contaminated particles, both in the respiratory tract and on exposed skin. A strict protocol should be followed, and staff should be thoroughly trained on each step. Practice sessions should be performed in order for staff to gain familiarity with the protocol and to assess competency in each aspect. Studies have shown that institutional training programs and proctored practice sessions significantly increase compliance with PPE (28). The importance of strict adherence to procedure as well as performing each step in a deliberate, unhurried manner should be stressed. Avoiding self-contamination while doffing is of the utmost importance and should be considered equally as important as correct donning. In a review of SARS infection control practices in six Toronto hospitals, $87 \%$ of healthcare workers infected after infection control precautions were implemented were unsure of how to properly don and doff their PPE (29). Removal of the PPE should be performed in a specific designated area, with the goal to ensure protection and prevent crosscontamination amongst healthcare personnel. Suggested donning and doffing sequence of both PPE and PAPR are shown in (Figure 2) (Video: Proper donning and doffing of PPE: https://youtu.be/_GWz5O773jk).

\section{General considerations for bronchoscopy in hospitalized patients with suspected or confirmed COVID-19}

Bronchoscopy is discouraged and should not be a first-line testing modality for patients with suspected COVID-19 infection. An evaluation of viral shedding in 18 patients infected with SARS-CoV-2 revealed higher viral loads in the nasal cavity than in the throat, a similar pattern to that of influenza (30). A recent case report from China describes a patient with a high-risk history who required 3 separate tests to diagnose COVID-19, the last of which was positive after 11 days of symptoms. Of note, the positive result was obtained via a nasal swab, not bronchoscopy (31). Bronchoscopy may be considered to obtain a diagnosis in intubated patients with suspected COVID-19 and negative nasal/oropharyngeal swab and tracheal aspirate testing if that information might alter clinical or operational management. A bronchoalveolar lavage (BAL) sensitivity of $93 \%$ compared to $72 \%$ in sputum and $63 \%$ in nasal swabs has been demonstrated in a cohort of COVID-19 patients (32). In situations requiring additional testing, the bronchoscopist will have to weigh the potential clinical value of the results carefully prior to proceeding.

As stressed in other sections of this document, bronchoscopy should be avoided, if at all possible, in patients with suspected or confirmed COVID-19 infection. That being said, there are several potential situations in which bronchoscopy may be considered, which are summarized in Table 3. This list was compiled based on discussions amongst the authors and providers with experience treating COVID-19 patients in China, Italy, and Iran, as well as a literature search for the use of bronchoscopy in other respiratory viral outbreaks. The largest body of literature regarding diagnostic testing is found in association with H1N1 influenza, although it consists mostly of case reports. Anecdotally, there has been extensive use of bronchoscopy in China during the first phase of the COVID-19 pandemic. Thus far, there is no organized report of the Chinese bronchoscopy experience during the outbreak available. As such the possible indications represent extrapolation from prior outbreaks.

Alternative diagnoses must still be considered even in the setting of an outbreak, some of which may be best detected by bronchoscopy. Metan et al. reported a renal transplant patient who was initially diagnosed with $\mathrm{H} 1 \mathrm{~N} 1$ influenza during an outbreak but who failed to respond to antimicrobial and antiviral treatment and subsequently was diagnosed with Pneumocystis jirovecii using a BAL specimen (33). Bronchoscopy may also have a role in diagnosing co-infections and COVID-19-related complications. Gabrilovich et al. reported a patient who was diagnosed with necrotizing tracheobronchitis secondary to MRSA co-infection in the setting of influenza H1N1 infection (34). Several authors have reported bronchoscopic detection of alveolar hemorrhage $(35,36)$ or organizing pneumonia (37) complicating influenza H1N1 infection. Furthermore, co-infection with other respiratory viruses, such as rhinovirus and influenza, as well as secondary bacterial infections, has been previously described in 
PPE Donning Procedure

(a) Gather supplies (gown, gloves, N95, eye protection). (b) Perform hand hygiene. (c) Don gown. Tie gown in back. (d) Don N95 respirator. (e) Don eye protection. (f) Don gloves.
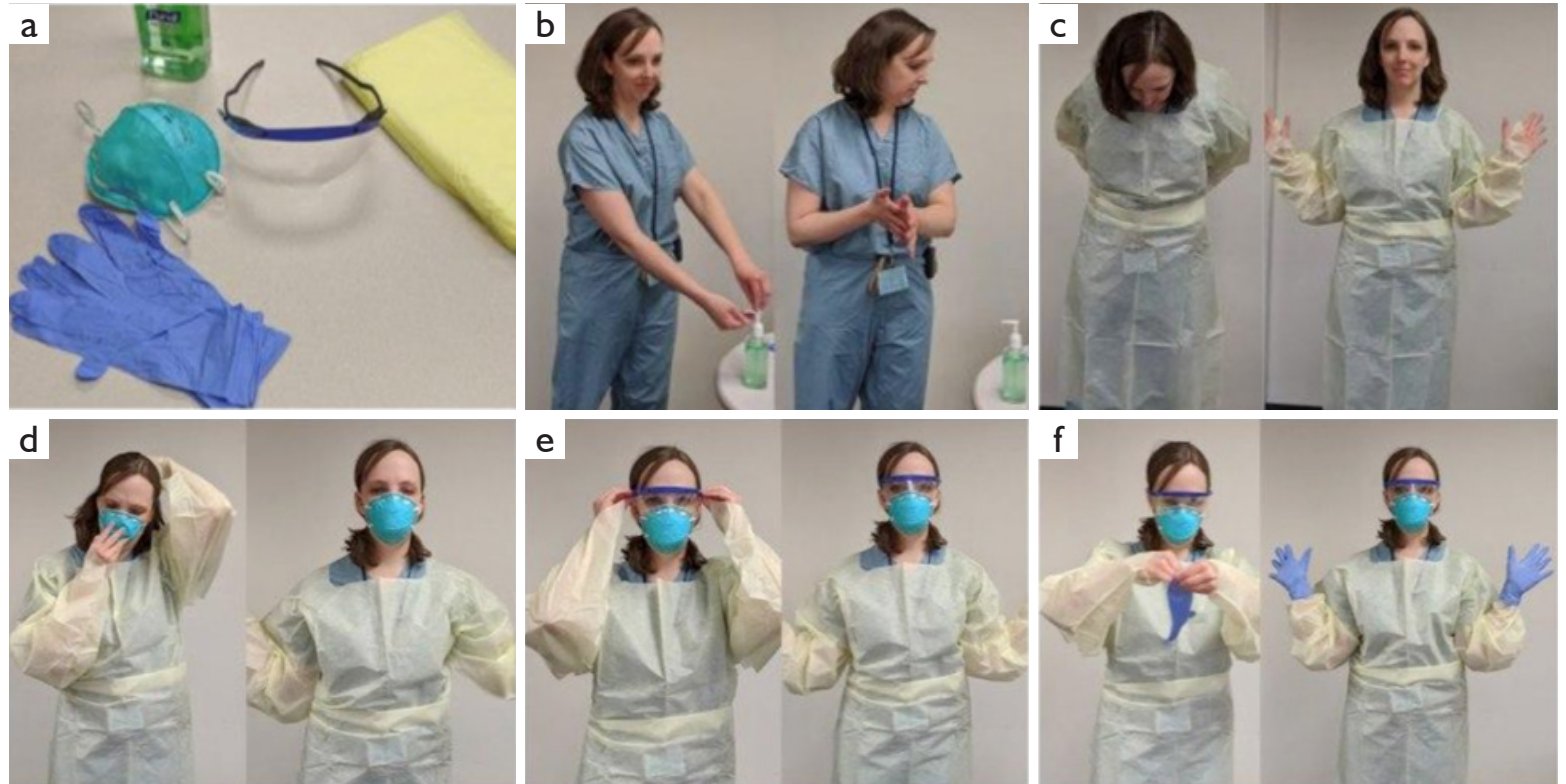

\section{PPE Doffing Procedure}

(a) Within patient room, take off gown and gloves together by pulling gown forward, roll gown and remove gloves at the same time. Do not touch the outside of the gown. (b) Perform hand hygiene. (c) Remove face shield by grabbing the sides, not the front. (d) Perform hand hygiene. Leave patient room. (e) Remove N95 by grabbing the straps and pulling forward. Do not touch the front. (f) Perform hand hygiene.
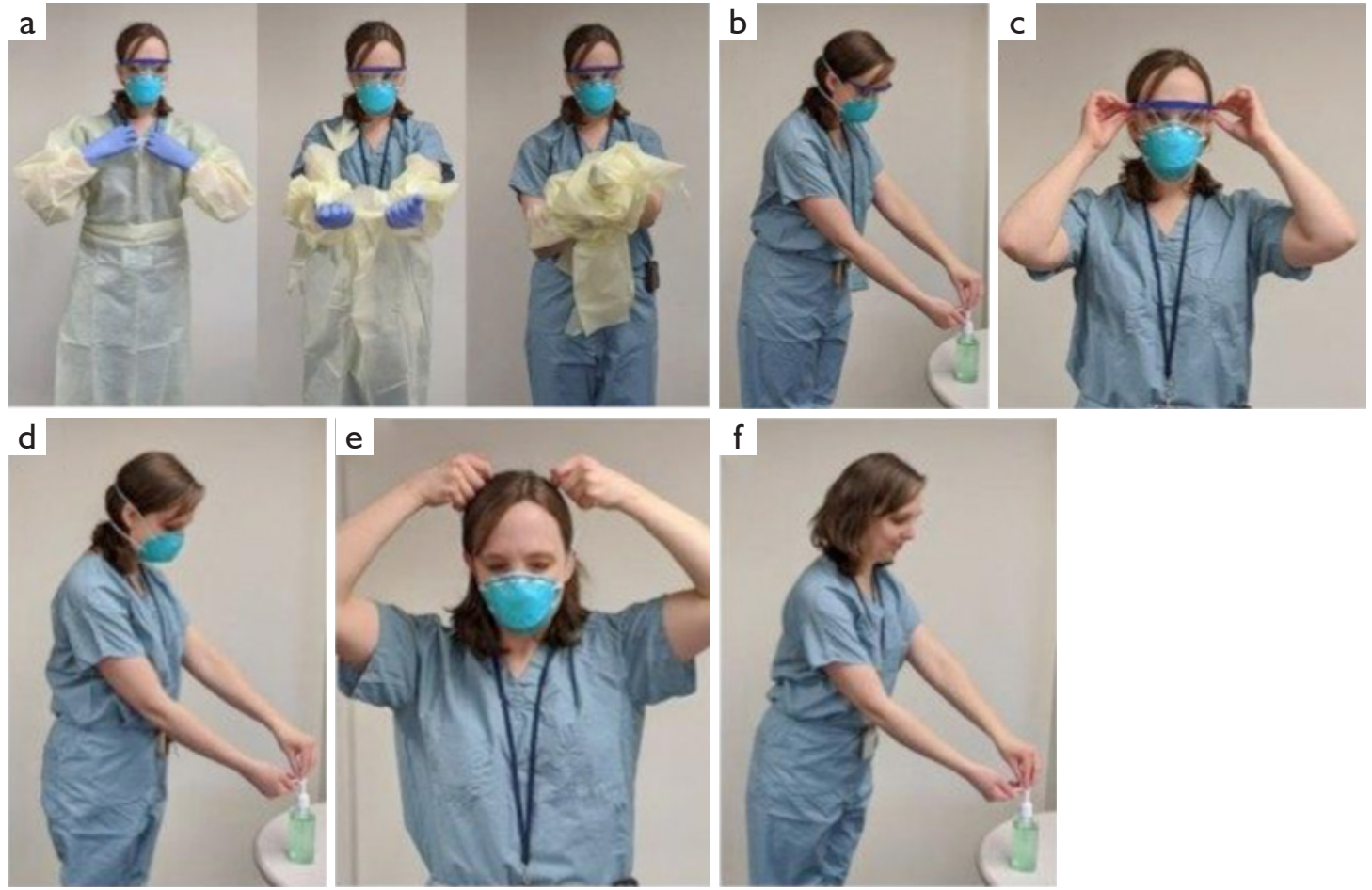


\section{PAPR Donning Procedure}

(a) Gather supplies (gown, gloves, and PAPR equipment/hood). (b) After hand hygiene, pick up and place the respirator at the small of the back and fasten the belt around the waist, securing any loose straps. (c) Don gown and then tie gown in back. (d) Don PAPR hood, ensuring a tight fit and connect tubing between powered respirator and hood. (e) Don gloves. (f) Final result.
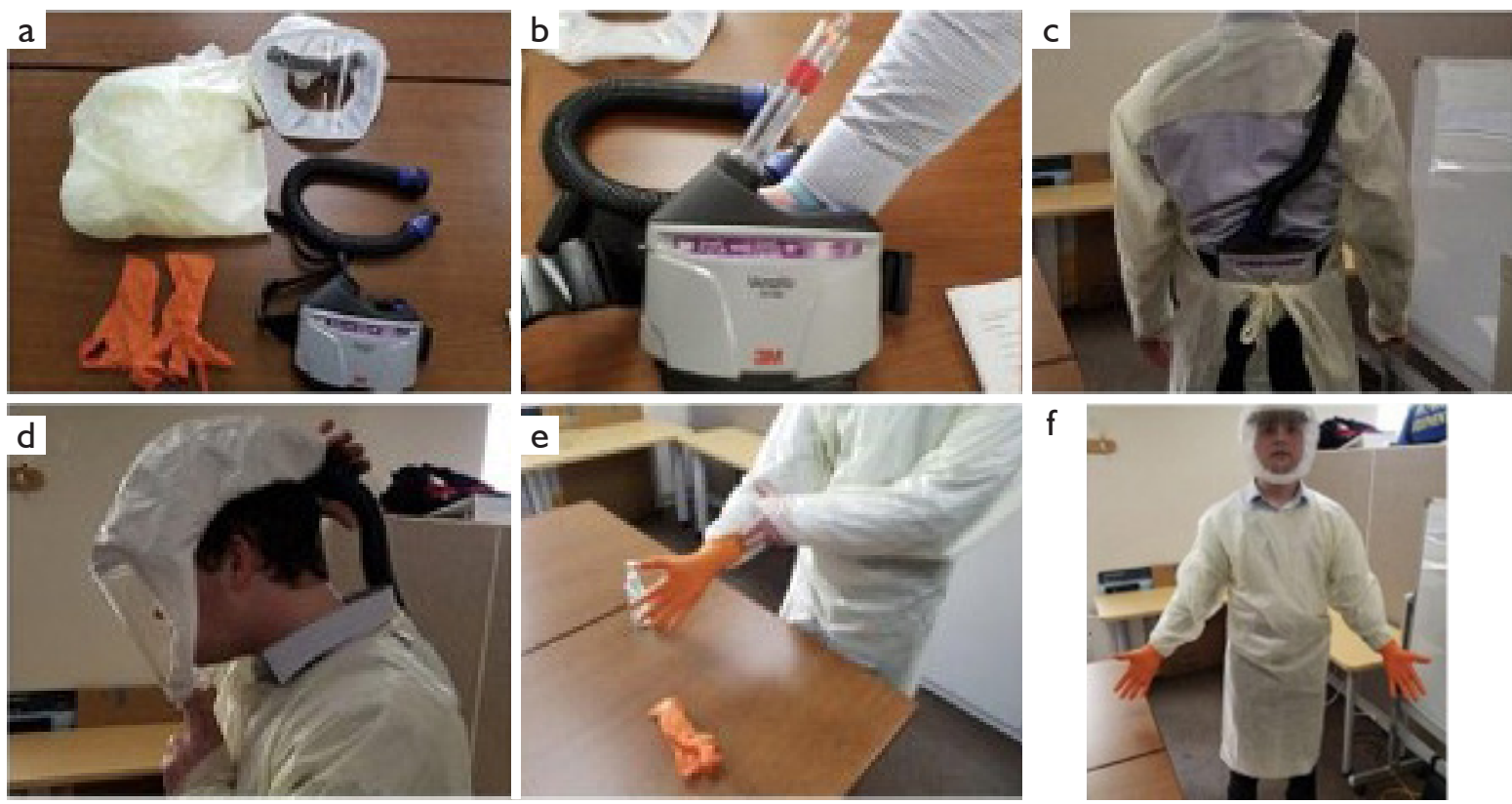

Figure 2 Donning and doffing PPE and PAPR. Reproduced with permission from Matthew Walter, Department of Infection Prevention and Epidemiology, University of Michigan. PPE, personal protective equipment; PAPR, powered air-purifying respirator.

Table 3 Potential indications for bronchoscopy in patients with suspected or confirmed COVID-19 after careful exclusion of nonbronchoscopic means

Potential diagnostic indications

- Additional testing in patients with suspected COVID-19 infection and negative nasal swabs

- Evaluation for alternative infection

- Evaluation for co-infection

- Complication evaluation

- Concurrent diagnosis evaluation

Potential therapeutic indications

- Therapeutic aspiration

outbreaks of coronavirus (MERS-CoV) and recently in COVID-19 by Ian Brown (38-42). As stated previously, the clinical benefit of using bronchoscopy to confirm a diagnosis of COVID-19 or detect co-infection or virusrelated complications must be carefully weighed against the risk of bronchoscopy in propagating infection.

Therapeutically, bronchoscopy will likely have a limited role in patients with suspected or confirmed COVID-19 infection. Pulmonary toileting-the use of bronchoscopy to prophylactically clean out respiratory secretions, usually in intubated patients-is a frequent practice in infectionassociated respiratory failure (43), though there is no literature supporting its use in the general population. There is some evidence supporting the use of toileting bronchoscopy in burn patients with pneumonia (44). We strongly recommend against the routine use of toileting bronchoscopy in COVID-19 patients. Therapeutic aspiration used to relieve bronchial obstruction with associated gas exchange consequences may be considered as an indication. This is especially true in light of anecdotal reports of occasional mucous impaction in some COVID-19 patients. There is precedent for this phenomenon in the literature in the setting of prior respiratory virus outbreaks. Personal communications with physicians in China, however, have reported primarily watery bronchial secretions in COVID-19 infections, akin to most ARDS patients, with thick secretions rarely seen and typically from a secondary cause (Jayuan Sun, MD, email communication, March 2020). Plastic bronchitis has been reported in 
several cohorts in the setting of H1N1 influenza and other viruses $(45,46)$. Development of plastic bronchitis can result in life-threatening gas exchange abnormalities that may need bronchoscopic intervention. The risks (for both the patient and associated healthcare workers) and benefits must be weighed individually on a case-by-case basis. As with any patient with severe hypoxemic respiratory failure, bronchoscopy may precipitate further decompensation and should be carefully considered prior to being performed.

\section{Staffing considerations}

Only essential personnel should participate in these highrisk procedures in order to minimize the potential exposure to aerosolized particles and fomites. Visitors and students should not be allowed to participate. Trainee involvement in suspected and confirmed cases will be individually dictated by each institution. These recommendations are fluid and we recognize that these guidelines may change during emergency situations or when staff is limited.

\section{Specimen handling}

The standard specimen containers should be placed in biohazard bags while following universal precautions (gloves, eye protection, and standard mask). All specimen transport to the laboratory should follow routine protocols including universal precautions. In cases of suspected or confirmed COVID-19 infection, we recommend proactive communication with the receiving laboratory by double bagging specimens and labeling them as suspected or confirmed COVID-19. Double bagging involves first bagging the specimen in the patient's room and then taking it out of the room and placing it into a separate pre-labeled specimen bag. Follow this process with immediate hand hygiene.

\section{Mini bronchoalveolar lavage (mini-BAL) and other alternatives to bronchoscopy}

In cases where bronchoscopy is being sought for alternative diagnosis, the use of protected mini-BAL can be considered as a substitute for traditional bronchoscopy. The technique involves insertion of a catheter or modified nasogastric tube through the endotracheal tube allowing for lower respiratory tract sampling. There is currently no published experience performing this procedure in patients with suspected or confirmed COVID-19. However, this technique has the potential to minimize the overall risk by reducing the number of healthcare workers and equipment present in the room. The test has shown similar bacteriological concordance to bronchoscopy for intubated patients with bacterial pneumonia (47) and ventilator-associated pneumonia (48); notably similar results were seen in immunocompromised patients for both bacterial and fungal etiologies (49). The clinical utility of mini-BAL in viral infections is not well understood. We have reason to believe, based on other chemical and biological markers, that the mini-BAL yield for lower airway cultures might be reasonably concordant with bronchoscopic methods for viral sampling (50). As there is currently no published experience performing this procedure with suspected or confirmed COVID-19 patients, we would consider this procedure in lieu of bronchoscopy if lower respiratory tract sampling was needed. Caution is advised when the catheter is both introduced and removed through the endotracheal tube adapter so as to minimize aerosolization of viral particles.

\section{Airway management and bronchoscopy in a patient with suspected or confirmed COVID-19}

Any airway manipulation or thoracic endoscopic procedure is considered an AGP and thus carries with it a high risk of infection to healthcare workers. In patients with suspected or confirmed COVID-19, increased vigilance and precaution must be taken in AGP to avoid contact with contaminated particles. In addition to standard practices listed above, such as hand hygiene, we recommend the following safety measures.

\section{PPE}

At a minimum, N95 masks and PPE (gloves, gown, face shield, and head cover) should be used for all suspected or confirmed cases of COVID-19 (see Table 2). A PAPR may also be used and may provide superior protection. N95 reuse or extended use is not recommended in these situations, however, we have seen widespread shortages of such protections and therefore these are considered extenuating circumstances where reuse or extended use may be necessary. Personal communication with physicians in heavily affected areas, such as Italy and China, reveal that many operators wear an N95 mask in combination with a PAPR out of an abundance of caution as droplet inhalation may occur during doffing. Based on data from the Ebola virus outbreak, $30 \%$ of experienced technicians would selfcontaminate when removing a PAPR (51). Despite this, 
there is not enough evidence to suggest this as standard practice; this practice may also contribute to PPE shortages. N95 masks are in limited supply and we see no problem with wearing a general surgical mask with a PAPR. Disposable head covers and beard covers should be properly worn to reduce the risk of contaminating hands by touching hair that may have been exposed to droplets during AGP. Disposable fluid-resistant long-sleeved gowns and disposable full-face shields are recommended for frontline medical staff at risk of exposure. Double gloving is recommended as it has been shown to dramatically reduce contamination of intraoperative equipment during intubation (52).

\section{Protocol for breach of PPE during an aerosol-generating procedure (AGP)}

In patients with suspected or confirmed COVID-19 infection, the interruption of protective barriers requires immediate action. If this occurs, the exposed provider should interrupt the procedure immediately and relinquish it to a different provider. Backup providers should be available, if possible, to take over and complete the procedure. The provider who was exposed should be quarantined for 10 days if the source patient is confirmed as positive for COVID-19 (53). During this time, self-monitoring with temperature checks and symptom evaluation should occur every 12 hours and should be documented longitudinally.

Supervision by occupational health or the designated infection control group at the given facility should be established. The decision to test for COVID-19 should be made by the designated infection control team. Every effort should be expended to ensure that the exposed healthcare provider receives the best available care. The provider should be allowed to return to duty after either 2 negative nasopharyngeal swabs and resolution of symptoms or after at least 7 days have passed since symptoms first appeared combined with 72 hours free of symptoms. Local conditions may dictate alterations in this guidance. If this situation occurs, we recommend immediate consultation with the hospital's designated infection control team.

\section{Procedural considerations}

We recommend avoiding all AGP in patients with suspected or confirmed COVID-19, however we recognize that this is not realistic. For each required procedure, we recommend the most experienced operator perform it, if possible, and that personnel be limited to an absolute minimum. PPE should be examined by a partner to ensure it is correct and properly placed. We do not recommend using highflow heated nasal cannula or non-invasive positive pressure modalities (CPAP, BiPAP) outside of a negative pressure environment as this is believed to increase the aerosolization of SARS-CoV-2. Emergent intubations should be avoided, if possible, to reduce the risk of improper donning and doffing of PPE. Awake intubation should be avoided as well as the use of any atomized or nebulized local anesthetic as this may aerosolize the virus. Immediately preceding intubation, all necessary equipment should be prepared next to the patient with a pre-specified plan for its disposal or decontamination in order to limit the travel distance of contaminated equipment. Assisting staff should be limited to those essential to the procedure in order to reduce exposure. Identical PPE protocols should be used for both intubation and extubation. Consider prophylactic antiemetics prior to extubation to reduce the risk of vomiting and possible viral spread.

We recommend rapid sequence intubation in order to avoid potential aerosolization of the viral particles followed by intubation with a video-laryngoscope to improve firstpass success. Care should be taken to avoid contact with any surface other than the equipment and the patient. Efforts should be made to limit bagging during the preoxygenation phase and again after the endotracheal tube is placed. Ensure the cuff is inflated before connecting to the ventilator. Consider limiting placement confirmation to end-tidal $\mathrm{CO}_{2}$, oxygen saturations and observation of equal chest rise. Auscultation should not be performed, and chest X-ray should be avoided if possible. After intubation, the operator's outer glove should be removed in order to place the soiled laryngoscope in it to reduce spread of contaminated particles (28). Equipment should be disposed of or decontaminated in accordance with each institution's biohazard materials policy. Once intubated, a HEPA filter should be placed in between the endotracheal tube and the ventilator circuit. HEPA filters should also be used in between facemasks and reservoir bags.

During bronchoscopy, both the length of the procedure and removal and reinsertion of the bronchoscope should be kept to a minimum (27). It has been suggested that during bronchoscopy active suctioning placed very close to the endotracheal tube swivel connector during insertion and removal of the bronchoscope may remove viral particles and, therefore, potentially decrease transmission risk by aerosolization. This process may also be replicated during connector exchanges. There is currently no data to support this practice, however, as it does not require any additional 
Table 4 Tracheostomy: procedure and precautions in patients with suspected or confirmed COVID-19 (adapted from Dr. Stephen Chinn, University of Michigan, Department of OtolaryngologyHead and Neck Surgery Guidelines)

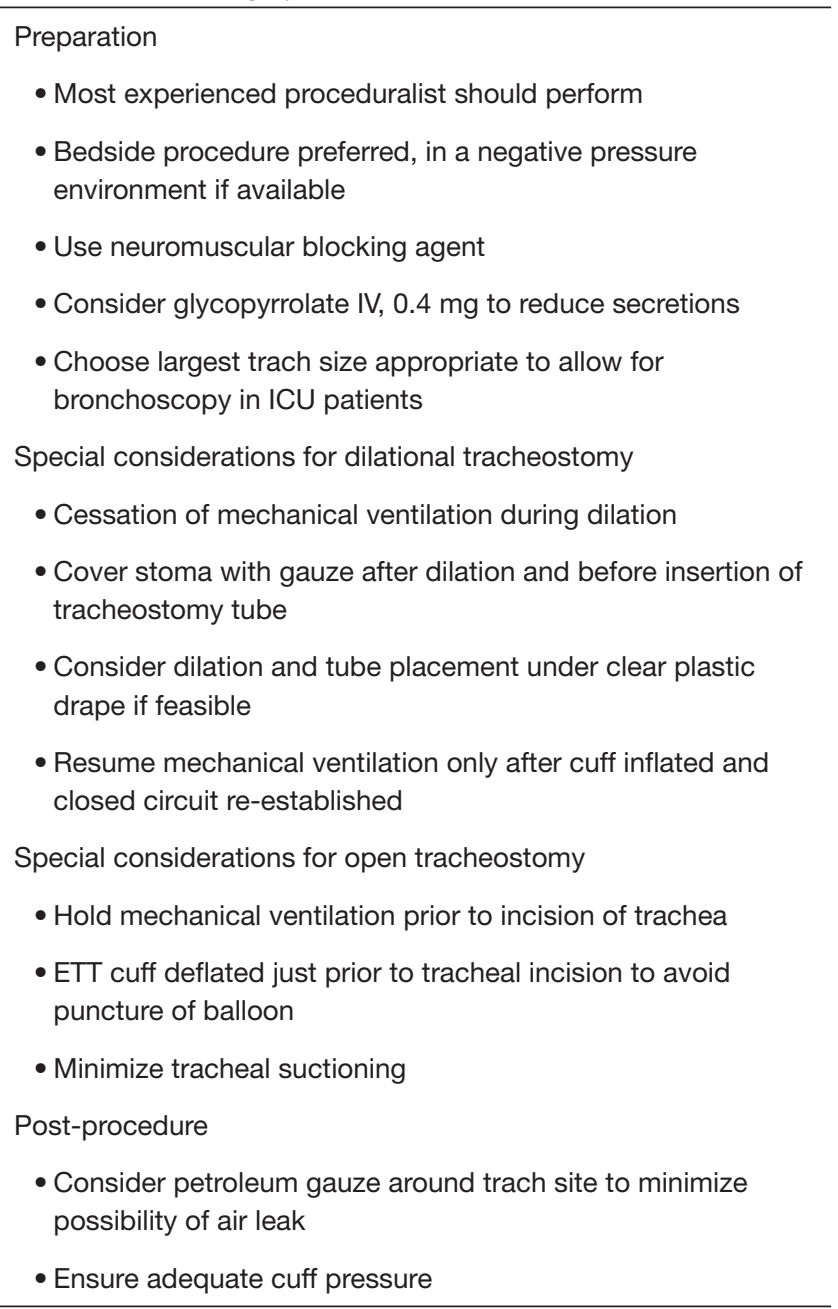

resources and poses no risk to the operators or support staff, we feel this may be justified at this time. Consideration should be given to suspending ventilation during insertion and removal of the bronchoscope. Rigid bronchoscopy should be avoided if possible, and if necessary, should be used without jet ventilation (27).

We recognize that more data is needed regarding bronchoscopy in the setting of COVID-19. To that end, we strongly encourage anyone performing bronchoscopy on patients with suspected or confirmed COVID-19 to upload data into the GPS (Global Pandemic SARS-CoV-2) Bronchoscopy Database (https://redcap.vanderbilt.edu/ surveys/?s=JCC4NAXD4K).
Tracheostomy is also a high-risk procedure due to aerosol generation. In general, this procedure should be deferred as long as possible due to high risk of infection of healthcare workers. We know from previous experience with the SARS outbreak that there may be patients in whom a tracheostomy becomes necessary throughout the course of this crisis (54). All patients in whom a tracheostomy is considered should ideally be negative for SARS-CoV-2 (55). If a rapid test is available and supplies are not limited, consideration can be given to requiring 2 negative tests, performed 24 hours apart. If tracheostomy is undertaken (open or percutaneous), a bedside procedure in a negative pressure room is preferred for infection control purposes. The same PPE and precautions as listed above for bronchoscopy and intubation should be strictly followed. There are critical procedural considerations and additional precautions for such a high-risk procedure to ensure the safety of all members of the healthcare team (Table 4). As always, careful consideration of the risks and benefits of the procedure must be undertaken.

\section{Airway management and bronchoscopy in patients not suspected of having COVID-19}

Because there are reports of transmission before symptoms are present, we suggest an escalation of standard precautionary practices, such as hand hygiene and PPE use. This guidance is subject to change relative to local supplies of these materials. We now see that some geographic areas are inundated with COVID-19 positive patients and in these areas of heavy community spread, it may be necessary to consider all patients as suspected of being infected with SARS-CoV-2. We also recommend alterations in the usual manner in which AGPs are performed

\section{PPE}

PPE should be available for all providers and appropriate protocols followed, as previously outlined. In addition to standard PPE (gown and gloves), we recommend a hair bonnet, full-face shield and N95 mask for AGP to reduce possible exposure to respiratory droplets or viral particles. PAPR may be substituted for an N95 mask and face shield if a properly fitted N95 is not available.

\section{Procedural considerations}

Several considerations should be taken when performing 
AGP, such as intubation, extubation, tracheostomy care and bronchoscopy, even in patients not suspected of having COVID-19.

Routine tracheostomy changes in patients with chronic tracheostomy tubes should be delayed unless there is malfunction of the tube itself. Changes are associated with strong cough reflex and aerosolization of secretions. Ventilation in patients with tracheostomy tubes should include a closed system and suction catheters in line with the tube.

\section{Infection control considerations for the use of bronchoscopes in suspected or confirmed COVID-19 patients}

Previous reports have shown possible cross-contamination of bronchoscopes, specifically for bacterial infections (56). Damage to the scopes, as well as inadequate reprocessing, has been implicated. Therefore, we must assume there is a risk of cross-contamination with SARS-CoV-2 under such conditions. Bronchoscopes are listed as "semi-critical devices" according to the Spaulding classification (57), as they do not enter the vascular system as critical devices do. However, a high-level disinfection process must be used at a minimum.

The SARS-CoV-2 virus has a lipid envelope structure that makes it more resistant to disinfection by enzymatic detergents; therefore, use of these cleaners alone is not sufficient for reuse of the bronchoscope. Additionally, all bronchoscopes should be carefully inspected after use, including undergoing a leak test. Any scope that fails the leak test should immediately be removed from service, as it is not possible to fully sterilize the scope. Only after the leak test is completed and passed should enzymatic cleaner be used on the scope. After this process, it is necessary for the scope to undergo high-level disinfection process or gas sterilization.

Guidance from the CDC outlines specific processes to follow for post-procedure cleaning/sterilization (58). These steps include pre-cleaning, leak-testing, manual cleaning, and visual inspection followed by disinfection/ sterilization. Proper storage and documentation are also an integral part of the reprocessing workflow. Detailed logs are recommended in the case of an outbreak or need for epidemiologic investigation. High-level disinfection can be done manually or by using an automated endoscope reprocessor. Any personnel handling a contaminated bronchoscope must wear PPE at all times including gown, gloves, mask and eye shield.

If the procedure is performed in an ICU or other nonendoscopy-related area, the scope must be externally wiped, and the channel should be flushed with water. PPE is required at all times during this procedure. The scope should then be placed in a sealed protective bag or container for transport to the reprocessing unit and labeled appropriately.

\section{Single-use (disposable) flexible bronchoscopes}

Considering the above information, it could be hypothesized that the use of a single-use, disposable bronchoscope might offer specific advantages. In addition to avoidance of reprocessing equipment, there may be other advantages to using a single-use bronchoscope. As most of these bronchoscopes are attached by a single cord to a monitor, less equipment is involved in set-up, post-procedure disinfection and transport (see Figure 3). Additionally, most single-use bronchoscopes would only need a single user to operate, which may decrease the number of personnel required to assist with the procedure. While there are multiple vendors who sell these singleuse bronchoscopes (Ambu, Glidescope), not every facility has access to this equipment, and thus local resources will dictate their use.

From a cross-contamination standpoint, assuming well-controlled reprocessing and an undamaged scope, it is unclear if a single-use bronchoscope truly offers any advantages over a standard flexible bronchoscope in the setting of a suspected or confirmed patient with COVID-19 infection. However, there are several other reasons that a single-use bronchoscope could offer advantages in this setting, as mentioned above. The traditional bronchoscope has its own advantages including operator familiarity and improved vision (including high definition on some systems). We therefore cannot make a specific strong recommendation for either platform, and defer to local factors.

After an AGP such as bronchoscopy or intubation, it is critical to ensure that a thorough decontamination of the area is performed. This includes all surfaces in the room as well as any equipment that was brought into the room. Recent literature shows that the SARS-CoV-2 virus can remain aerosolized for up to 3 hours and can be found on surfaces for up to 3 days, depending on the surface type (59). Questions regarding room turnover time will depend on how many air changes per hour occur in the given room at 

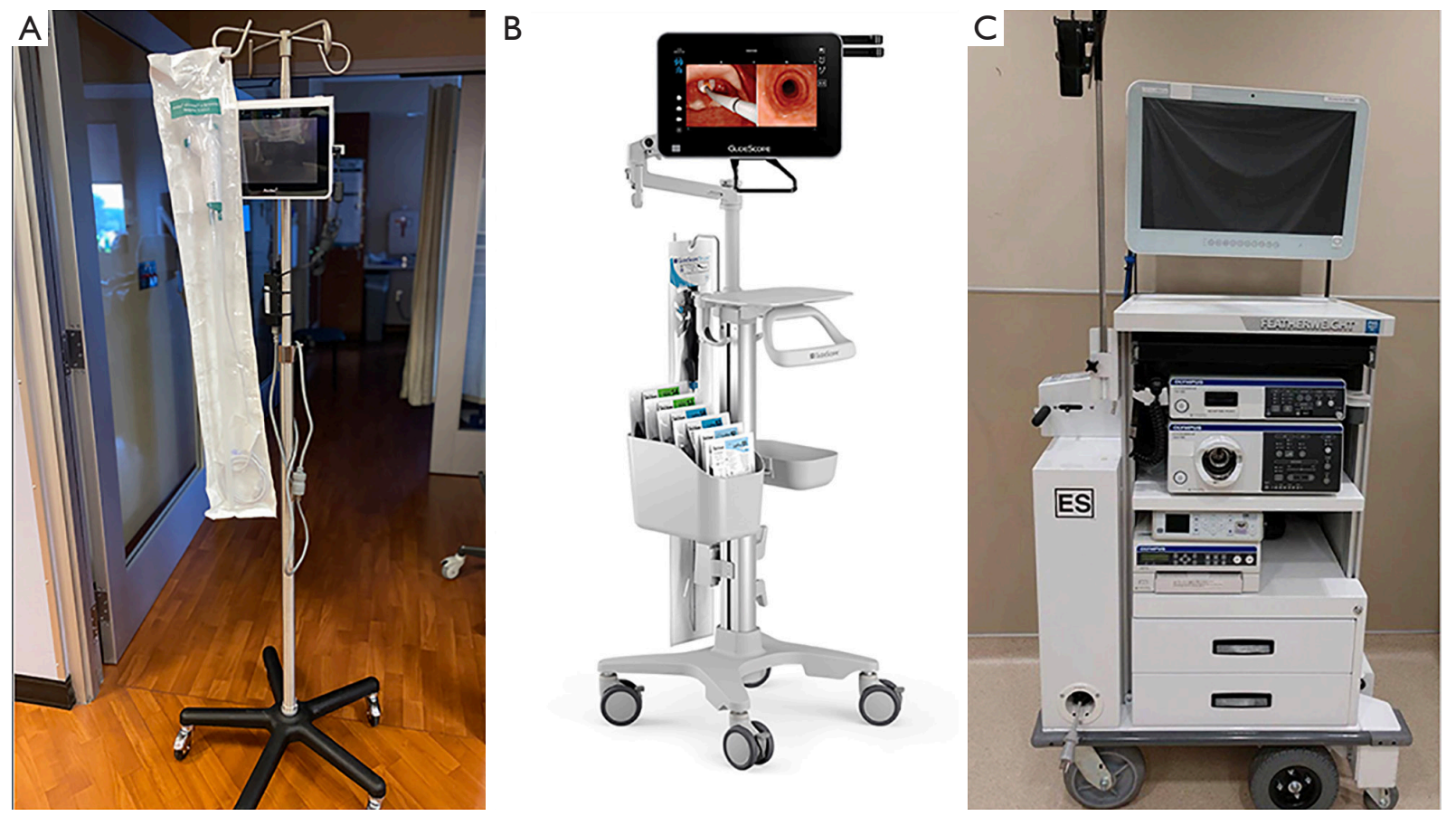

Figure 3 Single-use flexible bronchoscopes compared to traditional flexible bronchoscope set-up. (A) Ambu ${ }^{\circledR}$ aScope ${ }^{\text {TM }}$ with aView ${ }^{\text {TM }}$ monitor; (B) Glidescope ${ }^{\circledR}$ BFlex $^{\mathrm{TM}}$; (C) Olympus ${ }^{\circledR}$ EVIS EXERA III ${ }^{\mathrm{TM}}$ platform.

each facility. According to the Facility Guidelines Institute's 2010 Guidelines for Design and Construction of Health Care Facilities, negative-pressure bronchoscopy rooms under construction or renovation require a minimum of 12 total air exchanges per hour in order to provide dilution and exhaust of contaminated air (60). At this rate, after 23 minutes $99 \%$ of particles will be exchanged and, after 35 minutes, $99.9 \%$ of particles will be exchanged (61). Existing facilities require a minimum of 6 total air exchanges per hour. These rooms require outside exhaust or HEPA-filtering if recirculated.

\section{Concluding remarks}

While hospital protocols are rapidly changing with the advent of the COVID-19 pandemic, core priorities remain-providing appropriate medical care to patients and protecting healthcare workers. In this document, we have outlined suggestions for bronchoscopy and airway management amid this global emergency. These recommendations are based on the most up to date literature available at the time of this writing. We have applied levels of evidence to each recommendation while acknowledging that randomized controlled trials are rarely available so early in a pandemic (Table 5). Therefore, some of this information has been extrapolated from similar viral outbreaks, as well as from published guidelines and expert opinion related to COVID-19. We would like to highlight that bronchoscopy is strongly discouraged in the vast majority of cases of suspected or confirmed COVID-19, though we have provided considerations and precautions that can be used if bronchoscopy is absolutely necessary. We also recognize the challenge in stratifying outpatient airway procedures in non-suspected COVID-19 patients and have outlined recommendations for classification according to indication and urgency. We believe that protection of healthcare staff is paramount and emphasize the many benefits of proper PPE use for specific clinical scenarios.

It is our intent that the recommendations and considerations below translate into a valuable resource to providers, institutions, organizations, patients, and communities we all serve. We recognize there are limitations in these guidelines, and we plan to release updated information from the literature as it becomes available. Lastly, we advocate for further research to advance the scientific knowledge of how to best cope with the challenges surrounding COVID-19. 
Table 5 Graded recommendations for bronchoscopy and airway management amid COVID-19 pandemic

\begin{tabular}{|c|c|}
\hline Recommendation & Grade \\
\hline - Review all procedures to assess indication and urgency & $1 \mathrm{C}$ \\
\hline - Stratification of outpatient bronchoscopic procedures (Figure 1) & $2 \mathrm{C}$ \\
\hline $\begin{array}{l}\text { - Screen all patients for COVID-19 symptoms prior to procedure and upon arrival; if positive, delayed the procedure until } \\
\text { clinically feasible }\end{array}$ & $1 \mathrm{C}$ \\
\hline - Avoid bronchoscopy in patients with suspected or known COVID-19, if possible & $1 \mathrm{C}$ \\
\hline - Consider bronchoscopy in selected situations (see Table 1) & $2 \mathrm{C}$ \\
\hline - Do not routinely perform toileting bronchoscopy in COVID-19 patients & $1 \mathrm{C}$ \\
\hline \multicolumn{2}{|l|}{ Specimen handling } \\
\hline $\begin{array}{l}\text { - In low-risk or COVID-19 negative patients, specimen transport to the laboratory follows routine protocols including universal } \\
\text { precautions }\end{array}$ & $1 \mathrm{C}$ \\
\hline $\begin{array}{l}\text { - In cases of suspected or confirmed COVID-19, proactively communicate with the receiving laboratory; double bag and label } \\
\text { specimens as suspected or confirmed COVID-19; follow with immediate hand hygiene }\end{array}$ & $1 \mathrm{C}$ \\
\hline \multicolumn{2}{|l|}{ Mini bronchoalveolar lavage (mini-BAL) and other alternatives to bronchoscopy } \\
\hline - Consider protected mini-BAL as a substitute for traditional bronchoscopy if lower respiratory tract sampling is needed & 2B \\
\hline \multicolumn{2}{|l|}{ PPE in non-suspected COVID-19 patients } \\
\hline \multicolumn{2}{|l|}{ PPE in suspected/known COVID-19 patients } \\
\hline $\begin{array}{l}\text { - Use N95 masks and PPE (gloves, gown, face shield, and head cover); a PAPR may also be used and may provide superior } \\
\text { protection }\end{array}$ & $1 \mathrm{C}$ \\
\hline - N95 reuse or extended use is not recommended & $1 \mathrm{C}$ \\
\hline - Double gloving is recommended & 2B \\
\hline \multicolumn{2}{|l|}{ Protocol for PPE breach during an AGP in suspected/known COVID-19 patients } \\
\hline - Exposed provider should interrupt the procedure immediately and relinquish it to a different provider & $1 \mathrm{C}$ \\
\hline - Exposed provider should be quarantined for 10 days if the source patient is confirmed as positive for COVID-19 & $2 \mathrm{C}$ \\
\hline - Return to work based on testing strategy or resolution of symptoms & $1 \mathrm{C}$ \\
\hline
\end{tabular}

Table 5 (continued) 
Table 5 (continued)

\begin{tabular}{|c|c|}
\hline Recommendation & Grade \\
\hline $\begin{array}{l}\text { - Avoid the use of aerosol generating systems including high-flow heated nasal cannula or non-invasive positive pressure } \\
\text { modalities (CPAP, BiPAP) }\end{array}$ & $1 \mathrm{C}$ \\
\hline - Avoid all AGP, if possible & $1 \mathrm{C}$ \\
\hline - If an AGP is necessary, the most experienced operator should perform it, if possible; limit personnel to an absolute minimum & $1 \mathrm{C}$ \\
\hline - Avoid awake intubation as well as the use of any atomized or nebulized local anesthetic & $1 \mathrm{C}$ \\
\hline - Intubate via rapid sequence intubation using a video-laryngoscope & $1 \mathrm{C}$ \\
\hline - Place a HEPA filter in between the endotracheal tube and the ventilator circuit once intubated & $2 \mathrm{C}$ \\
\hline \multicolumn{2}{|l|}{ Infection control for the use of bronchoscopes in suspected/known COVID-19 patients } \\
\hline - Perform high-level disinfection or gas sterilization on all bronchoscopes; enzymatic detergents alone are not sufficient & 1B \\
\hline - Carefully inspect all bronchoscopes after use, and perform a leak test & $1 \mathrm{C}$ \\
\hline $\begin{array}{l}\text { - Any personnel handling a contaminated bronchoscope must wear PPE at all times including gown, gloves, mask and eye } \\
\text { shield }\end{array}$ & $1 \mathrm{C}$ \\
\hline $\begin{array}{l}\text { - Consider a single-use bronchoscope, though this is not superior to an undamaged traditional bronchoscope which undergoes } \\
\text { well-controlled reprocessing }\end{array}$ & $2 \mathrm{C}$ \\
\hline - Thoroughly decontaminate the area after the AGP & $1 \mathrm{C}$ \\
\hline
\end{tabular}

\section{Acknowledgments}

The authors thank Laurie LaRusso, MS, ELS, for editorial assistance paid for by the Society for Advanced Bronchoscopy. We also wish to thank Dr. Stephen Chinn, University of Michigan, Department of Otolaryngology-Head and Neck Surgery, for assistance with considerations for tracheostomy. Funding: None.

\section{Footnote}

Conflicts of Interest: All authors have completed the ICMJE uniform disclosure form (available at http://dx.doi. org/10.21037/jtd.2020.04.32). MAP reports personal fees from Medtronic, BodyVision, Intuitive Surgical, Philips, Biodesix, AstraZeneca, Johnson \& Johnson, United Therapeutics, Actelion, Pfizer, Ambu, and Boston Scientific and other from Inivata, all outside the submitted work; his wife is an employee of Medtronic. $\mathrm{AB}$ reports personal fees from Cook Medical and Change Healthcare, outside the submitted work. JDC reports personal fees from Restor 3D, Medtronic, Cook Medical, other from Intuitive Surgical, and personal fees and other from Pinnacle Biologics, outside the submitted work. GC reports personal fees from Boston Scientific, Medtronic, Pinnacle Biologics, Restor 3D, and grants from Intuitive Surgical, all outside the submitted work. GCN reports personal fees from Auris - Consulting for robotic bronchoscopy, outside the submitted work. CFP has nothing to disclose. JS reports personal fees from Somnoware Sleep Solutions and Medtronic, Inc, outside the submitted work. JT reports personal fees from Olympus/ Spiration, outside the submitted work. MZ reports personal fees from Pulmonx, outside the submitted work. EF reports personal fees from Medtronic and Boston Scientific and grants from Intuitive Surgical, outside the submitted work. CLO has no conflicts of interest to declare.

Ethical Statement: The authors are accountable for all 
aspects of the work in ensuring that questions related to the accuracy or integrity of any part of the work are appropriately investigated and resolved.

Open Access Statement: This is an Open Access article distributed in accordance with the Creative Commons Attribution-NonCommercial-NoDerivs 4.0 International License (CC BY-NC-ND 4.0), which permits the noncommercial replication and distribution of the article with the strict proviso that no changes or edits are made and the original work is properly cited (including links to both the formal publication through the relevant DOI and the license). See: https://creativecommons.org/licenses/by-nc-nd/4.0/.

\section{References}

1. Centers for Disease Control and Prevention. Coronavirus Disease 2019 (COVID-19) Situation Summary. Updated March 15, 2020. Available online: https://www.cdc.gov/ coronavirus/2019-ncov/cases-updates/summary.html. Accessed March 16, 2020.

2. Atkins D, Best D, Briss PA, et al. Grading quality of evidence and strength of recommendations. BMJ 2004;328:1490.

3. Guan WJ, Ni ZY, Hu Y, et al. Clinical Characteristics of Coronavirus Disease 2019 in China. N Engl J Med 2020. [Epub ahead of print].

4. Li Q, Guan X, Wu P, et al. Early Transmission Dynamics in Wuhan, China, of Novel Coronavirus-Infected Pneumonia. N Engl J Med 2020. [Epub ahead of print].

5. European Centre for Disease Prevention and Control Technical Report. Infection prevention and control for COVID-19 in healthcare settings - March 2020. ECDC: Stockholm; 2020. Available online: https://www.ecdc. europa.eu/sites/default/files/documents/COVID-19infection-prevention-and-control-healthcare-settingsmarch-2020.pdf. Access March 16, 2020.

6. World Health Organization. Report of the WHO-China Joint Mission on Coronavirus Disease 2019 (COVID-19). 16-24 February 2020. Available online: https://www.who.int/ docs/default-source/coronaviruse/who-china-joint-missionon-covid-19-final-report.pdf. Accessed March 16, 2020.

7. Wang D, Hu B, Hu C, et al. Clinical Characteristics of 138 Hospitalized Patients With 2019 Novel CoronavirusInfected Pneumonia in Wuhan, China. JAMA 2020. [Epub ahead of print].

8. Ai T, Yang Z, Hou H, et al. Correlation of Chest CT and RT-PCR Testing in Coronavirus Disease 2019
(COVID-19) in China: A Report of 1014 Cases. Radiology 2020. [Epub ahead of print].

9. Rothe C, Schunk M, Sothmann P, et al. Transmission of 2019-nCoV Infection from an Asymptomatic Contact in Germany. N Engl J Med 2020;382:970-1.

10. Wu Z, McGoogan JM. Characteristics of and Important Lessons From the Coronavirus Disease 2019 (COVID-19) Outbreak in China: Summary of a Report of 72314 Cases From the Chinese Center for Disease Control and Prevention. JAMA 2020. [Epub ahead of print].

11. Serna-Gallegos D, Mercado F, Imai T, et al. Effects of time from completed clinical staging to surgery: does it make a difference in stage 1 non-small cell lung cancer? [abstract 67]. American Association for Thoracic Surgery; April 28May 1, 2018; San Diego, CA.

12. Rosenthal DI, Liu L, Lee JH, et al. Importance of the treatment package time in surgery and postoperative radiation therapy for squamous carcinoma of the head and neck. Head Neck 2002;24:115-26.

13. American College of Surgeons. COVID-19: Elective Case Triage Guidelines for Surgical Care. Online March 24, 2020. Available at: https://www.facs.org/covid-19/clinicalguidance/elective-case. Accessed March 25, 2020.

14. Centers for Disease Control and Prevention. Interim Infection Prevention and Control Recommendations for Patients with Suspected or Confirmed Coronavirus Disease 2019 (COVID-19) in Healthcare Settings. Available online: https://www.cdc.gov/coronavirus/2019ncov/infection-control/control-recommendations.html. Accessed March 16, 2020.

15. Tran K, Cimon K, Severn M, et al. Aerosol generating procedures and risk of transmission of acute respiratory infections to healthcare workers: a systematic review. PLoS One 2012;7:e35797.

16. Interventional Respiratory Group, Respiratory Branch, Chinese Medical Association. Guidelines for the development of bronchoscopy during the prevention and control of new coronavirus infections in 2019 (Trial) [J/ OL]. Chinese Journal of Tuberculosis and Respiratory Diseases, 2020, 43 (2020-02-08). Available online: http:// rs.yiigle.com/yufabiao/1180118.htm

17. Munoz-Price LS, Bowdle A, Johnston BL, et al. Infection prevention in the operating room anesthesia work area. Infect Control Hosp Epidemiol 2018. doi: 10.1017/ ice.2018.303.

18. Anesthesia Patient Safety Foundation. Perioperative Considerations for the 2019 Novel Coronavirus (COVID-19). February 12, 2020. Available online: https:// 
www.apsf.org/news-updates/perioperative-considerationsfor-the-2019-novel-coronavirus-covid-19/. Accessed March 16, 2020.

19. Centers for Disease Control and Prevention. Facial Hairstyles and Filtering Facepiece Respirators. Available online: https://www.cdc.gov/niosh/npptl/pdfs/ FacialHairWmask1 1282017-508.pdf. Accessed March 16, 2020.

20. Radonovich LJ Jr, Simberkoff MS, Bessesen MT, et al. N95 Respirators vs Medical Masks for Preventing Influenza Among Health Care Personnel: A Randomized Clinical Trial. JAMA 2019;322:824-33.

21. Kamming D, Gardam M, Chung F. Anaesthesia and SARS. Br J Anaesth 2003;90:715-8.

22. Neuman BW, Adair BD, Yoshioka C, et al. Supramolecular architecture of severe acute respiratory syndrome coronavirus revealed by electron cryomicroscopy. J Virol 2006;80:7918-28.

23. Loeb M, Dafoe N, Mahony J, et al. Surgical mask vs N95 respirator for preventing influenza among health care workers: a randomized trial. JAMA 2009;302:1865-71.

24. Yang S, Lee GW, Chen CM, et al. The size and concentration of droplets generated by coughing in human subjects. J Aerosol Med 2007;20:484-94.

25. Morawska L. Droplet fate in indoor environments, or can we prevent the spread of infection? Indoor Air 2006; 16:335-47.

26. Loeb M, McGeer A, Henry B, et al. SARS among critical care nurses, Toronto. Emerg Infect Dis 2004;10:251-5.

27. Le DH, Bloom SA, Nguyen QH, et al. Lack of SARS transmission among public hospital workers, Vietnam. Emerg Infect Dis 2004;10:265-8.

28. Moore D, Gamage B, Bryce E, et al. Protecting health care workers from SARS and other respiratory pathogens: organizational and individual factors that affect adherence to infection control guidelines. Am J Infect Control 2005;33:88-96.

29. Ofner-Agostini M, Gravel D, McDonald LC, et al. Cluster of cases of severe acute respiratory syndrome among Toronto healthcare workers after implementation of infection control precautions: a case series. Infect Control Hosp Epidemiol 2006;27:473-8.

30. Zou L, Ruan F, Huang M, et al. SARS-CoV-2 Viral Load in Upper Respiratory Specimens of Infected Patients. N Engl J Med 2020;382:1177-9.

31. Ruan ZR, Gong P, Han W, et al. A case of 2019 novel coronavirus infected pneumonia with twice negative 2019$\mathrm{nCoV}$ nucleic acid testing within 8 days. Chin Med J (Engl)
2020. [Epub ahead of print].

32. Wang W, Xu Y, Gao R, et al. Detection of SARS-CoV-2 in Different Types of Clinical Specimens. JAMA 2020. [Epub ahead of print].

33. Metan G, Bozkurt I, Koc AN. Pneumocystis jiroveci pneumonia (PCP) misdiagnosed as pandemic influenza H1N1 in a renal transplant patient. Infez Med 2011;19:182-4.

34. Gabrilovich MI, Huff MD, McMillen SM, et al. Severe Necrotizing Tracheobronchitis From Panton-Valentine Leukocidin-positive MRSA Pneumonia Complicating Influenza A-H1N1-09. J Bronchology Interv Pulmonol 2017;24:63-6.

35. Gilbert CR, Vipul K, Baram M. Novel H1N1 influenza A viral infection complicated by alveolar hemorrhage. Respir Care 2010;5 5:623-5.

36. Toolsie O, Tehreem A, Diaz-Fuentes G. Influenza A Pneumonia Associated with Diffuse Alveolar Hemorrhage. A Case Report and Literature Review. Am J Case Rep 2019;20:592-6.

37. Gomez-Gomez A, Martinez-Martinez R, Gotway MB. Organizing pneumonia associated with swine-origin influenza A H1N1 2009 viral infection. AJR Am J Roentgenol 2011;196:W103-4.

38. WHO MERS-Cov Research G. State of Knowledge and Data Gaps of Middle East Respiratory Syndrome Coronavirus (MERS-CoV) in Humans. PLoS Curr 2013. doi: 10.1371/currents.outbreaks.0bf719e352e7478f8ad85fa 30127 ddb8.

39. Zaki AM, van Boheemen S, Bestebroer TM, et al. Isolation of a novel coronavirus from a man with pneumonia in Saudi Arabia. N Engl J Med 2012;367:1814-20.

40. Bermingham A, Chand MA, Brown CS, et al. Severe respiratory illness caused by a novel coronavirus, in a patient transferred to the United Kingdom from the Middle East, September 2012. Euro Surveill 2012;17:20290.

41. Drosten C, Seilmaier M, Corman VM, et al. Clinical features and virological analysis of a case of Middle East respiratory syndrome coronavirus infection. Lancet Infect Dis 2013;13:745-51.

42. Shah N, Brown I. Higher co-infection rates in COVID19. Available at: https://medium.com/@nigam/higher-coinfection-rates-in-covid19-b24965088333. Accessed March 19, 2020.

43. Alifano M, Gaucher S, Rabbat A, et al. Alternatives to resectional surgery for infectious disease of the lung: from embolization to thoracoplasty. Thorac Surg Clin 
2012;22:413-29.

44. Carr JA, Phillips BD, Bowling WM. The utility of bronchoscopy after inhalation injury complicated by pneumonia in burn patients: results from the National Burn Repository. J Burn Care Res 2009;30:967-74.

45. Deng J, Zheng Y, Li C, et al. Plastic bronchitis in three children associated with 2009 influenza A(H1N1) virus infection. Chest 2010;138:1486-8.

46. Zhang J, Kang X. Plastic bronchitis associated with influenza virus infection in children: a report on 14 cases. Int J Pediatr Otorhinolaryngol 2015;79:481-6.

47. Kollef MH, Ward S. The influence of mini-BAL cultures on patient outcomes: implications for the antibiotic management of ventilator-associated pneumonia. Chest 1998;113:412-20.

48. Leo A, Galindo-Galindo J, Folch E, et al. Comparison of bronchoscopic bronchoalveolar lavage vs blind lavage with a modified nasogastric tube in the etiologic diagnosis of ventilator-associated pneumonia. Med Intensiva 2008;32:115-20.

49. Tasbakan MS, Gurgun A, Basoglu OK, et al. Comparison of bronchoalveolar lavage and mini-bronchoalveolar lavage in the diagnosis of pneumonia in immunocompromised patients. Respiration 2011;81:229-35.

50. Lavigne MC. Nonbronchoscopic Methods [Nonbronchoscopic Bronchoalveolar Lavage (BAL), MiniBAL, Blinded Bronchial Sampling, Blinded Protected Specimen Brush] to Investigate for Pulmonary Infections, Inflammation, and Cellular and Molecular Markers: A Narrative Review. Clinical Pulmonary Medicine 2017;24:13-25.

51. Mumma JM, Durso FT, Ferguson AN, et al. Human Factors Risk Analyses of a Doffing Protocol for EbolaLevel Personal Protective Equipment: Mapping Errors to Contamination. Clin Infect Dis 2018;66:950-8.

52. Birnbach DJ, Rosen LF, Fitzpatrick M, et al. Double gloves: a randomized trial to evaluate a simple strategy to reduce contamination in the operating room. Anesth Analg 2015;120:848-52.

53. Centers for Disease Control and Prevention. Interim domestic guidance for management of exposures to Severe Acute Respiratory Syndrome (SARS) for healthcare and other institutional settings. March 27, 2003. Available online: https://stacks.cdc.gov/view/cdc/25042. Accessed March 16, 2020.
54. Wei WI, Tuen HH, Ng RW, et al. Safe tracheostomy for patients with severe acute respiratory syndrome. Laryngoscope 2003;113:1777-9.

55. ENT UK. Guidance for Surgical Tracheostomy and Tracheostomy Tube Change during the COVID-19 Pandemic. March 19, 2020. Available at: https://www. entuk.org/tracheostomy-guidance-during-covid-19pandemic. Accessed March 25, 2020.

56. Ofstead CL, Quick MR, Wetzler HP, et al. Effectiveness of Reprocessing for Flexible Bronchoscopes and Endobronchial Ultrasound Bronchoscopes. Chest 2018;154:1024-34.

57. Rutala WA, Weber DJ. Disinfection of endoscopes: review of new chemical sterilants used for high-level disinfection. Infect Control Hosp Epidemiol 1999;20:69-76.

58. Healthcare Infection Control Practices Advisory Committee. Essential Elements of a Reprocessing Program for Flexible Endoscopes - The Recommendations of the Healthcare Infection Control Practices Advisory Committee (HICPAC). 2016. Available online: https:// www.cdc.gov/hicpac/pdf/flexible-endoscopereprocessing. pdf. Accessed March 16, 2020.

59. van Doremalen N, Bushmaker T, Morris D, et al. Aerosol and surface stability of $\mathrm{HCoV}-19$ (SARS-CoV-2) compared to SARS-CoV-1. medRxiv 2020. doi.org/10.1101/2020.03. 09.20033217.

60. Centers for Disease Control and Prevention. Guidelines for Environmental Infection Control in Health-Care Facilities (2003). Background C. Air. Available online: https:// www.cdc.gov/infectioncontrol/guidelines/environmental/ background/air.html. Accessed March 16, 2020.

61. Centers for Disease Control and Prevention. Guidelines for Environmental Infection Control in Health-Care Facilities (2003). Appendix B. Air. Available online: https:// www.cdc.gov/infectioncontrol/guidelines/environmental/ appendix/air.html\#tableb1. Accessed March 16, 2020.

Cite this article as: Pritchett MA, Oberg CL, Belanger A, De Cardenas J, Cheng G, Cumbo Nacheli G, Franco-Paredes C, Singh J, Toth J, Zgoda M, Folch E. Society for Advanced Bronchoscopy Consensus Statement and Guidelines for bronchoscopy and airway management amid the COVID-19 pandemic. J Thorac Dis 2020;12(5):1781-1798. doi: 10.21037/ jtd.2020.04.32 